\title{
A Cognitive Skill Classification Based on Multi Objective Optimization Using Learning Vector Quantization for Serious Games
}

\author{
Moh. Aries Syufagi ${ }^{1,2}$, Mochamad Hariadi ${ }^{3}$ \& Mauridhi Hery P. ${ }^{3}$ \\ ${ }^{1}$ Multimedia Studies Program, Public Vocational High School 1 Bangil Pasuruan \\ ${ }^{2}$ Department of Information, STMIK Yadika Bangil, \\ ${ }^{3}$ Electrical Department, Faculty of Industrial Technology ITS Surabaya \\ Email: moh.aries.syufagi@gmail.com, mochar@ee.its.ac.id,hery@ee.its.ac.id
}

\begin{abstract}
Nowadays, serious games and game technology are poised to transform the way of educating and training students at all levels. However, pedagogical value in games do not help novice students learn, too many memorizing and reduce learning process due to no information of player's ability. To asses the cognitive level of player ability, we propose a Cognitive Skill Game (CSG). CSG improves this cognitive concept to monitor how players interact with the game. This game employs Learning Vector Quantization (LVQ) for optimizing the cognitive skill input classification of the player. CSG is using teacher's data to obtain the neuron vector of cognitive skill pattern supervise. Three clusters multi objective target will be classified as; trial and error, carefully and, expert cognitive skill. In the game play experiments employ 33 respondent players demonstrates that $61 \%$ of players have high trial and error, $21 \%$ have high carefully, and $18 \%$ have high expert cognitive skill. CSG may provide information to game engine when a player needs help or when wanting a formidable challenge. The game engine will provide the appropriate tasks according to players' ability. CSG will help balance the emotions of players, so players do not get bored and frustrated.
\end{abstract}

Keywords: cognitive skill classification; learning vector quantization; multi objective; serious game.

\section{$1 \quad$ Introduction}

Games and game technology are aimed to transform the way we educate and train students at all levels. Education and information, skill training, even political and religious beliefs can be communicated via video games. Somehow, these games and repurposed game technology, collectively called "serious games," have yet to be fully embraced by educators [1]. It means that not every educator is aware of the existence and advantage of serious game.

From previous research, we know that the serious game support the education process. Marsh, et al. [2] and Clark [3] stated that serious game is learning

Received September $30^{\text {th }}, 2010$, Revised June $15^{\text {th }}, 2011,2^{\text {nd }}$ Revision July $9^{\text {th }}, 2011$, Accepted for publication October $15^{\text {th }}, 2011$.

Copyright (C) 2011 Published by LPPM ITB, ISSN: 1978-3086, DOI: 10.5614/itbj.ict.2011.5.3.3 
through games which contain pedagogical aspects and is part of e-learning tools/media [4],[5],[6]. Clark [3], Arnseth [7] and Smith [8] further states that learning method using game is better then the conventional one since animations of learning material in game activates students' long term memories.

Serious games, like every other tool of education, must be able to show that the necessary learning has occurred. Specifically, games that teach also need to be games that test. Fortunately, serious games can build on both the long history of traditional assessment methods and the interactive nature of video games to provide testing and proof of teaching [1]. In other words, we can say that serious games should be reliable as a teaching aid as well as an assessment device.

In contras, Clark [9] in Evaluating the Learning and Motivation Effects of Serious Games explains that the tests of learning are often unreliable and invalid. Learning cannot be measured by self report, because there is an opportunity to manipulate data. In this research we propose the Cognitive Skill Game (CSG) to eliminate the data manipulation of learning tests in serious games. CSG is a model of indirect measurement of cognitive levels. CSG is a players' cognitive characteristics measurement by observing the players' cognitive behavior. The value of cognitive behavior can be taken from the indicators that appear when a game takes place.

On the other hand, game learning has an inverse relationship with learning test in many instances. Clark [9] gives details, pedagogy in games is often based on unguided discovery such as; minimal guidance and only high skill works, overwhelming discovery evidence without any assistance for beginners/novices learners [10],[11], discovery technique design and some game cause memory overwork and decrease the learning process [12].

Overload will not occur if the level of cognitive skill players is controlled. Inal, \& Cagiltay [13] explain the research of Csikszentmihalyi who emphasized the balance between an individual's skills and difficulties of tasks. He theorizes that the occurrence of flow experiences depends on this balance, and that if the balance does not exist between the individual's skills and the task, flow experiences will not occur. It is because heavier duty will cause faster frustration while too easy challenge will cause faster boredom. Typical assessments are likely to disrupt flow experience in immersive games. Thus there is a need for embedded assessments that would be less obtrusive and hence less disruptive to flow experience [14].

Proper classification of cognitive skills can be used to control the level of difficulty of the game. Providing an appropriate level of difficulty to the level of 
cognitive skill in a game scenario will balance the emotions of players. We can not provide an appropriate difficulty level of task if the cognitive skills of players are unknown. CSG is used to cluster cognitive skill process when the player is playing the serious game.

In previous studies, researchers have suggested the cognitive architecture and cognitive model [15],[16]. CBR (Case-Based-Reasoning), as conceptualized in rule-based classification and similarity-based classification, is the technical counterpart of psychological exemplar-based reasoning [16]. Conde \& Thalmann [16] propose the concept of a Learning Unit Architecture that function as a control unit of the AVAs' brain (Autonomous Virtual Agents). Both [15],[16] are Non Player Character (NPC) agent, the cognitive skill of which are applied into behavioral animation and machine learning agent. CSG improves this cognitive concept to monitor how players interact with the game. In other studies, Conati \& Klawe [17] proposed SIAs (Socially Intelligent Agents) architecture to support Game-Based Collaborative Learning. These agents are active game characters that can generate tailored interventions to stimulate students' learning and engagement by taking into account the student's cognitive states, as well as the student's meta-cognitive skill and emotional reaction. But do not involve elements of teachers' values in the calibration of cognitive.

Based on previous research [15],[16],[17], this project presents two original contributions that make this approach generic in serious game. The first contribution is proposes a method for embedding assessments in immersive games to reveal the behavior of player's cognitive skills. The second contribution is a complementary the serious game with embedded sensitivity of teachers to classification the cognitive skill.

In an ongoing global research, we will construct the pedagogic engine for all game which is called game pedagogic (shown in Figure 1.). The purpose of this research is to give a new alternative to know the players' cognitive skill. CSG is a part of pedagogic game, which is a model of cognitive measurement on a serious game. CSG can support the decisions of pedagogic game engine to give a reward or warnings to the player when the serious game is being played. The game engine will provide the appropriate tasks according to players' ability. CSG will help balance the emotions of players, so players do not get bored and frustrated. The balance emotion of the players strongly supports the procedural learning in a serious game.

CSG is Pedagogic Player Character (PPC) based on artificial intelligent agent. CSG can forecast the cognitive character of players. Learning Vector Quantization (LVQ) method is used in CSG. LVQ is used to classify players' 
the cognitive level. The teachers' data are neuron vector to use in learning or supervising data in LVQ method. Three multi objective classifications in CSG are; trial and error, carefully, and expert cognitive skill. In this research, students are respondent players demonstrates.

\section{Cognitive Skill Game}

Empirical studies have shown that although video and computer games are usually highly engaging and they have the potential educational tools, they often do not trigger the constructive reasoning necessary for learning. Conati \& Klawe [17] have a preliminary architecture (SIAs architecture) to improve the effectiveness of collaborative educational game. The architecture relies on the usage of socially intelligent agents that calibrate their interventions by taking into account not only the students' cognitive state, but also their emotional states and the unfolding of collaborative interactions within the game. They have presented a preliminary architecture based on Bayesian networks and influence diagrams. However, they have not explained the methods used to detect level of cognitive players' ability.

In several ongoing studies, Conde \& Thalmann [16] introduce AVA learning in which an AVA automatically learns an unknown cognitive model. They have developed a novel technique to achieve AVA learning using a tree search with a $k$-nearest neighbors (k-NN) method. Whereas, Bosch, et al. [15] argued that in variety of cognitive task rule-based classification and similarity-based classification mechanisms interact. They discussed several examples from Cognitive Psychology, AI and Semantics.

In addition to the development of cognitive research in the game [1],[2],[3],[4],,5],[6],[7],[8],[9],[10],[11],[12],[15],,[16],[17], there are also some researchers use LVQ method for data classification in game [18],[19],[20],[21]. CSG based on two phenomena (cognitive game and LVQ in game) are developed.

The CSG position in pedagogic game engine is shown in Figure 1 by the block with dark color. Two important parts of the game pedagogic engine are; i) artificial intelligent pedagogic and ii) autonomous pedagogic. The artificial intelligent pedagogic is used to observe the behavior of the players. There are four behaviors observed, including; i) players' motivation, i) players' cognitive, iii) players' time response, and iv) mistake goal of players. Autonomous pedagogic will provide a response to the behavior patterns of the players by providing feedback in the form of task and guidance automatically. 


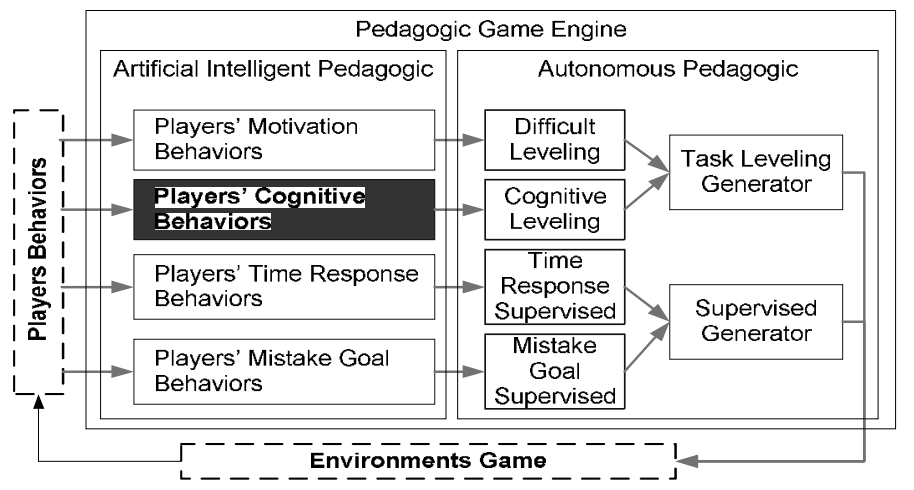

Figure 1 Pedagogic game engine structure.

CSG is a game that measures the level of players' cognitive process-based. This gives more emphasis on the achievement level of ability, for example; calculating the number of correct and incorrect items, and the competence by considering the weight of error, truth, and cancellation. The weakness of the measurement-based results is not considering players' characteristics of the action in completing the mission in the game. Players' game characteristics are in the forms of cognitive skills in the process.

The result of the cognitive skill classification is used to classify the cognitive level of task in game engine. The method of cognitive leveling in game engine is using the algorithm which will adapt the cognitive skill classification. The accuracy of classification results will determine the accuracy of the game engine to provide the appropriate level of difficulty of the task in the task level generator. CSG supported achievement balance between an individual's skills and difficulties of tasks. CSG can prevent boredom and frustration.

CSG is divided into three parts, namely; high cognitive skill (expert), middle cognitive skill (carefully), and low cognitive skill (trial and error). Those parts have a tendency of multi-objective due to the parameters that appears from each contrasted indicator.

\section{$3 \quad$ Design System and Method}

Design system of CSG is illustrated in a classifier structure and modeling functions use the LVQ method.

\subsection{Classifier Structure}

CSG represented in a classifier structure is shown in Figure 2 and Table 1. Three elements of CSG structure are; i) Identify Players Behavior, ii) 
Classification of Cognitive Skill Players and iii) Pattern of Cognitive Skill Players.

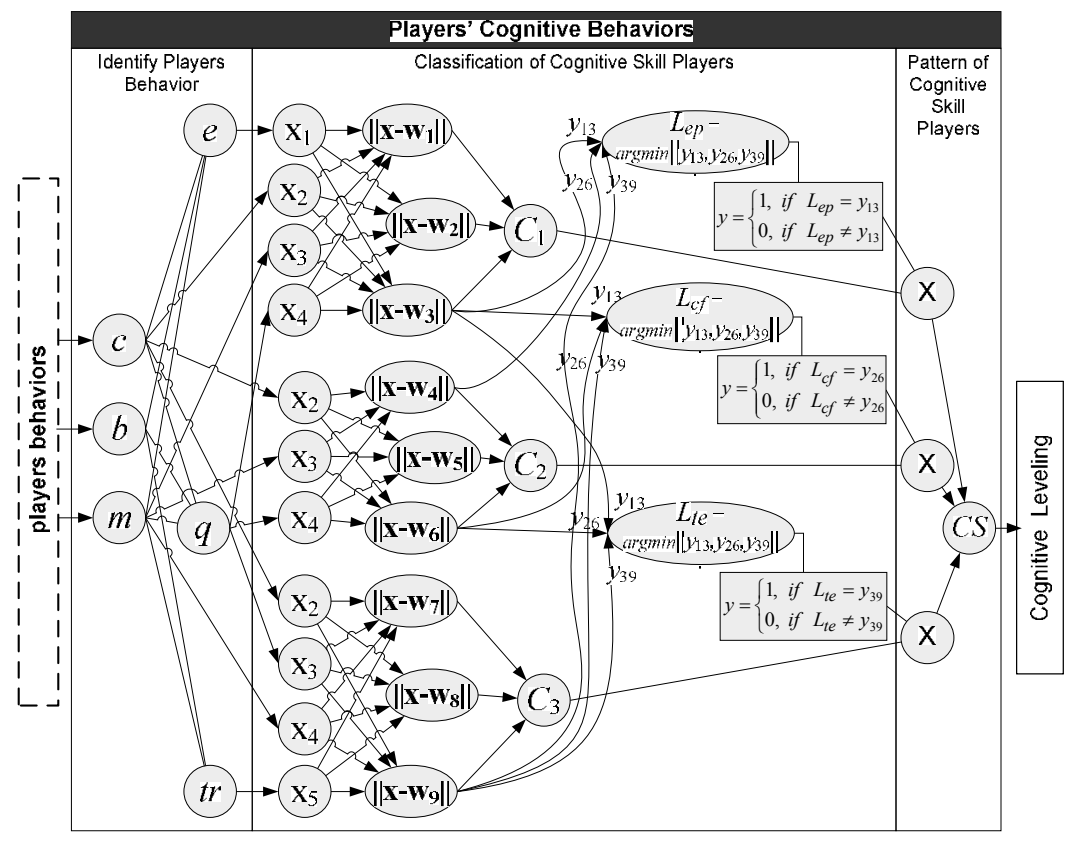

Figure 2 Classifier cognitive skill structure.

Table 1 Notation of classifier cognitive skill structure.

\begin{tabular}{|c|c|c|c|}
\hline Notation & Description & Notation & Description \\
\hline$c$ & $\begin{array}{l}\text { Input from Players (Number of Uncertainty (cancel) / } \\
\text { to Decline (escape)) }\end{array}$ & $\mathbf{w}_{\mathbf{2}}$ & Weight vector of Semi Expert $\left(\mathbf{w}_{j, e p}\right.$ for $\left.j=2\right)$ \\
\hline$b$ & $\begin{array}{l}\text { Input from Players (Number of Correct Answers / } \\
\text { Number of Victory in the Game) }\end{array}$ & $\mathbf{w}_{3}$ & Weight vector of High Expert $\left(\mathbf{w}_{j, e p}\right.$ for $j=3$ ) \\
\hline$m$ & Input from Players (Number of Wrong / Lost) & $\mathbf{w}_{4}$ & Weight vector of Low Careful $\left(\mathbf{w}_{j, c f}\right.$ for $\left.j=1\right)$ \\
\hline$e$ & Value of Players Ability / Self Efficacy & $\mathbf{w}_{5}$ & Weight vector of Semi Careful $\left(\mathbf{w}_{j, c f}\right.$ for $\left.j=2\right)$ \\
\hline$q$ & Value of Players Pick Question / Playing the Game & $\mathbf{w}_{6}$ & Weight vector of High Careful $\left(\mathbf{w}_{j, c f}\right.$ for $j=3$ ) \\
\hline$t r$ & Value of Players Try to Answer / Try to Finish & $\mathbf{w}_{7}$ & Weight vector of Low Trial and Error $\left(\mathbf{w}_{j, t e}\right.$ for $\left.j=1\right)$ \\
\hline $\mathrm{x}_{1}$ & Input vector of Self Efficacy / Ability $(e)$ & $\mathbf{w}_{8}$ & Weight vector of Semi Trial and Error $\left(\mathbf{w}_{j, t e}\right.$ for $\left.j=2\right)$ \\
\hline $\mathrm{x}_{2}$ & $\begin{array}{l}\text { Input vector of Uncertainty (cancel) / to Decline } \\
\text { (escape) }(c)\end{array}$ & $\mathbf{W}_{9}$ & Weight vector of High Trial and Error $\left(\mathbf{w}_{j, t e}\right.$ for $j=3$ ) \\
\hline $\mathrm{X}_{3}$ & Input vector of Wrong / Lost $(\mathrm{m})$ & $C_{1}$ & Class of Expert Level Classification $\left(C_{j, e p}\right)$ \\
\hline $\mathrm{x}_{4}$ & Input vector Pick Question / Playing the Game ( $q$ ) & $C_{2}$ & Class of Careful Level Classification $\left(C_{j, c f}\right)$ \\
\hline $\mathrm{x}_{5}$ & Input vector Try to Answer / to Finish (tr) & $C_{3}$ & Class of Trial and Error Level Classification $\left(C_{j, t e}\right)$ \\
\hline$\left\|\mathbf{x}-\mathbf{w}_{\mathbf{n}}\right\|$ & Distance between the input vector $(\mathbf{x})$ and weight & $y_{13}$ & Output of High Expert ( $\left.e p_{3}\right)$ \\
\hline & vector $\left(\mathbf{w}_{\mathbf{n}}\right)$ in competitive layer (hidden layer) & $y_{26}$ & Output of High Careful $\left(c f_{3}\right)$ \\
\hline $\mathbf{x}$ & input vector $\left(\mathbf{x}=\left\{\mathrm{x}_{1}, \mathrm{x}_{2} \ldots \mathrm{x}_{5}\right\}\right)$ & $y_{39}$ & Output of High Trial and Error $\left(t e_{3}\right)$ \\
\hline $\mathbf{w}_{\mathbf{n}}$ & weight vector for the nth output unit & $L$ & Cognitive Skill Type \\
\hline $\mathbf{w}_{1}$ & Weight vector of Low Expert ( $\mathbf{w}_{j, e p}$ for $j=1$ ) & $C S$ & Classification of CSG \\
\hline
\end{tabular}


For example $A$ is Cognitive Steps containing all skill contest with tests forms or all competitions items in the game. The number of skill contest (test) / competition (game) is $A=\{b, m, c\} . b, m$, and $c$ are players' parameter in playing the game. $b$ is the number of correct answers in the tests or the number of victory in the game, $m$ is the number of mistakes in the tests or the number of lost in the game, and $c$ is the number of hesitation (failure) in the tests or step back (escape) from competition in the game.

$t r=\{b, m\}$ is the condition when players try to answer a number of tests or try to finish all competition of CSG modeling which is also the indication of players' correct item/ victory and mistakes/ lost.

$$
t r=\frac{b+m}{2}
$$

$e=\{0.5 b, 0.3 m, 0.2 c\}$ is self efficacy or ability and also $q=\{b, m, c\}$ is the number of picking up questions from all of tests or playing all competition in the game, that is the content of players' characters in mistakes, correct items, and doubts in game.

$$
\begin{aligned}
e & =0.5 b+0.3 m+0.2 c \\
q & =\frac{b+m+c}{3}
\end{aligned}
$$

Three domains CSG are; i) trial and error domain, ii) carefully domain and iii) expert domain. $q \in t e, t r \in t e, t e=\{\{b, m, c\},\{b, m\}, m, c\}$ is trial and error domain which contains picking up question, trying to answer, mistakes, and uncertainty. $q \in c f, c f=\{\{b, m, c\}, m, c\}$ is carefully domain which contains picking up question mistakes, and uncertainty. Whereas, $q \in e p, e \in e p, e p=\{\{b, m, c\},\{0.5 b, 0.3 m$, $0.2 c\}, m, c\}$ is expert domain which contains picking up question, self efficacy, mistakes, and uncertainty. To classify this domain is using LVQ method.

$\mathrm{L}=(s, j)$ is CSG representative, $s$ is the notation of three domain in CSG, and $j$ is three level in every domain. L has nine probability out comes, those are ; i) low trial and error, ii) semi trial and error, iii) high trial and error, iv) low carefully, v) semi carefully, vi) high carefully, vii) low expert, viii) semi expert and ix) high expert.

\subsection{LVQ Method}

Many methods can be used for classifying data. Learning Vector Quantization (LVQ) is the data classification method used in this research. LVQ is supervised Artificial Neural Network (ANN) using competitive learning method developed 
by Kohonen, et al. [22], used in guided training from layers in ANN competition. Competitive layers will automatically learn to improve the classification of input vector performance periodically. When some input has very close distance vectors, those vectors will be grouped in the some class.

$$
\mathbf{c}=\arg \min \left\|\mathbf{x}-\mathbf{w}_{j}\right\|
$$

The algorithm of LVQ includes learning and recalling processes. In the learning process, in order to achieve accurate classification, Euclidean distance $\left(D_{i}\right)$ was utilized as a basic rule of competition [23].

$$
D_{j}=\left\|\mathbf{x}-\mathbf{w}_{j}\right\|=\sqrt{\sum_{i}\left(\mathbf{x}_{i}-\mathbf{w}_{i j}\right)^{2}}
$$

LVQ is used to classify data of input vector in CSG into three clusters. The input vector of LVQ is the weight of variables in CSG, namely; weight of trying to answer, picking up questions, competency, errors, and cancellation. The outcome of LVQ are three clusters of cognitive skill data type, namely; trial and error (te), careful ( $c f)$ and expert (ep) cognitive skill with three levels of clusters each. Those levels are high, middle and low cognitive skill.

$$
\begin{aligned}
& \mathbf{x}_{2, t e} \Leftrightarrow c, \mathbf{x}_{3, t e} \Leftrightarrow m, \mathbf{x}_{4, t e} \Leftrightarrow q, \mathbf{x}_{5, t e} \Leftrightarrow t r \\
& t e_{j}=\sqrt{\sum_{i}\left(\mathbf{x}_{i, t e}-\mathbf{w}_{i j, t e}\right)^{2}} \\
& C_{j, t e}=\arg \min \left\|\mathbf{x}_{t e}-\mathbf{w}_{j, t e}\right\|
\end{aligned}
$$

$t e_{j}$ is the value of trial and error in CGS, and $C_{j, t e}$ is the classification of trial and error level. Three classes of trial and error are $j=\{1,2,3\}$, in which; i) the value of $j$ is equal to one at $j$,te for low condition of trial and error representation index, ii) semi trial and error index will be presented with $j$ having value is two at $j, t e$, and iii) three is value of $j$ at $j$,te for index of high trial and error conditions. The variables $q, t r, m$ and $c$ for trial and error have weight $(\mathbf{w})$. The weight of te in $j$ class is $\mathbf{w}_{j, t e}$.

$c f_{j}$ is value of careful variable in $\mathrm{CSG}, C_{j, c f}$ is the classification of careful level. Three careful classes are $j=\{1,2,3\}$ in which; i) $j$ value which is one at $j, c f$ is used as a representation index for low careful, ii) $j$ which is two at $j, c f$ is index for semi careful and iii) $j$ which is three at $j, c f$ is the index for high careful. The weight of $c f$ in $j$ class is $\mathbf{w}_{j, c f}$. 


$$
\begin{aligned}
& \mathrm{x}_{2, c f} \Leftrightarrow c, \mathbf{x}_{3, c f} \Leftrightarrow m, \mathbf{x}_{4, c f} \Leftrightarrow q \\
& c f_{j}=\sqrt{\sum_{i}\left(\mathbf{x}_{i, c f}-\mathbf{w}_{i j, c f}\right)^{2}} \\
& C_{j, c f}=\arg \min \left\|\mathbf{x}_{c f}-\mathbf{w}_{j, c f}\right\|
\end{aligned}
$$

$e p_{j}$ is value expert variable in CSG in which $C_{j, e p}$ is the classification of expert level. Three expert classes are $j=\{1,2,3\}$ where; i) $j$ which is one at $j, e p$ variable is the index for low expert, ii) $j$ which is two at $j$,ep is the index for semi expert, and iii) $j$ which is three at $j, e p$ is index for high expert. The weight of $e p$ in $j$ class is $\mathbf{w}_{j, e p}$.

$$
\begin{aligned}
& \mathrm{x}_{1, e p} \Leftrightarrow e, \mathrm{x}_{2, e p} \Leftrightarrow c, \mathbf{x}_{3, e p} \Leftrightarrow m, \mathrm{x}_{4, e p} \Leftrightarrow q \\
& e p_{j}=\sqrt{\sum_{i}\left(\mathbf{x}_{i, e p}-\mathbf{w}_{i j, e p}\right)^{2}} \\
& C_{j, e p}=\arg \min \left\|\mathbf{x}_{e p}-\mathbf{w}_{j, e p}\right\|
\end{aligned}
$$

Some researchers use the optimum method based on LVQ [24],[25]. $L$ is classification of $C S$ optimum conditions. $L$ is defined at three probability optimum conditions, namely; i) trial and error, ii) careful, and iii) expert. $C S$ is the classification of CSG outcome that can be defined at nine probability optimum conditions, namely; i) high trial and error, ii) semi trial and error, iii) low trial and error, iv) high careful, v) semi careful, vi) low careful, vii) high expert, viii) semi expert, and ix) low expert.

$$
\begin{aligned}
& L=\arg \min \left\|\left\{t e_{3}, c f_{3}, e p_{3}\right\}\right\| \\
& C S=\left\{\begin{array}{l}
C_{j, t e}, \text { if } L=t e_{3} \\
C_{j, c f}, \text { if } L=c f_{3} \\
C_{j, e p}, \text { if } L=e p_{3}
\end{array}\right.
\end{aligned}
$$

$L$ is considered as trial and error if high trial and error $\left(t e_{3}\right)$ value is smaller than high careful $\left(c f_{3}\right)$ and smaller than high expert $\left(e p_{3}\right)$ too, then $C S$ is low trial and error if $C_{j, t e}$ value is close to low trial and error value. $C S$ is semi trial and error if $C_{j, t e}$ value is close to semi trial and error value and then $C S$ is high trial and error if $C_{j, t e}$ value is close to high trial and error value. 
The description of $L$ is careful is when the value of high careful $\left(c f_{3}\right)$ is smaller than high trial and error $\left(t e_{3}\right)$ and smaller than high expert $\left(e p_{3}\right)$ too. $C S$ is low careful if $C_{j, c f}$ value is close to low careful value, $C S$ is semi careful if $C_{j, c f}$ value is close to semi careful value, and $C S$ is high careful if $C_{j, c f}$ value is close to high careful value.

$L$ is expert outcome probabilities which is obtained if the value of high expert $\left(e p_{3}\right)$ is smaller than high trial and error $\left(t e_{3}\right)$ and smaller than high careful $\left(c f_{3}\right)$ too, then $C S$ is low expert if $C_{j, e p}$ value is close to low expert value. $C S$ is semi expert if $C_{j, e p}$ value is close to semi expert value, and $C S$ is high expert if $C_{j, e p}$ value is close to high expert value.

\section{Experiment}

We conducted a survey to twenty teachers to obtain three characteristic of cognitive skill. The aims of choosing teachers as the respondents is to get the ideal cognitive skill characteristics based on the assumption that teachers are the best cognitive skill evaluator. The other consideration is that teachers have the qualification as pedagogic assessors which is shown by their diplomas, certificates, and teaching experience. Therefore, teachers are reliable in determining the parameters of cognitive skill indicators.

The population is senior high school teachers that consist of two groups, twelve respondents are the math and science teachers, and eight respondents are the social teachers.

Teachers will give weight of the variable reference can influence the value of type $(L)$ and class $(C)$ of cognitive skills. Variable reference from teachers includes; pick questions $(q)$, try to answer $(t r)$, self efficacy $(e)$, mistake $(m)$, and cancels $(c)$.

Parameters of cognitive skill characteristic value can be used as a cognitive skill reference. The reference of cognitive skill is the value of ideal cognitive skills. Values of the parameters in the cognitive skill reference data obtained from the classification of the teachers' survey data. Data of cognitive skill characteristic from teachers will be applied on learning rate of the LVQ cognitive skill pattern.

Populations of cognitive skill classification in this research are 33 pupils, including; 18 male and 15 female. The respondents are students in a senior high school. The ages of respondents are ranged from 16 to 19 years old. Respondents are used to test the CSG system. CSG base on LVQ will classify the students cognitive. 
Value of $b, m$, and $c$ is taken when students play the game. The variable of $b, m$, and $c$ are players' characteristic of cognitive behavior. These variables are the input of CSG.

\section{$5 \quad$ Result}

\subsection{Value of Cognitive Skills}

CSG is embedded in sensitivity of teachers in the game. It is because CSG data training is taken from the teachers. The data observation from the teacher is ideal data that can be used as training data in LVQ method. LVQ training outcome is used as weight value reference of cognitive skill classification. Table 2 is the result of LVQ training (from data teachers) which includes; weight of pick questions $(q)$, weight of try to answers $(t r)$, weight of self efficacy $(e)$, weight of mistake $(m)$, and weight of cancels $(c)$. The value of Table 2 is a reference weight value of cognitive skills in the CSG. The Table value is showing the character of cognitive skill reference which is in accordance with the players' character.

In Eqs. 6 and 7, the trial and error cognitive skill reference shows the weight of $q$ in $j$ class is $w_{1 j . t e}=\{0.12,0.82,0.84\}$, the weight of $t r$ in $j$ class is $w_{2 j, t e}=\{0.12,0.80,0.79\}$, the weight of $m$ in $j$ class is $w_{3 j, t e}=\{0.12,0.82,0.82\}$, and the weight of $c$ in $j$ class is $w_{4 j, t e}=\{0.31,0.85,0.11\}$.

Table 2 Weight of cognitive skill reference.

\begin{tabular}{ccccccc}
\hline $\begin{array}{c}\text { pick } \\
\text { questions } \\
(\boldsymbol{q})\end{array}$ & $\begin{array}{c}\text { tray to } \\
\text { answers } \\
(\boldsymbol{t r})\end{array}$ & $\begin{array}{c}\text { self } \\
\text { efficacy } \\
(\boldsymbol{e})\end{array}$ & $\begin{array}{c}\text { mistake } \\
(\boldsymbol{m})\end{array}$ & $\begin{array}{c}\text { cancels } \\
(\boldsymbol{c})\end{array}$ & $\begin{array}{c}\text { class } \\
(\boldsymbol{C})\end{array}$ & $\begin{array}{c}\text { cognitive skill } \\
\text { type } \\
(\boldsymbol{L})\end{array}$ \\
\hline 0.119625 & 0.124634 & - & 0.124744 & 0.310473 & low & \\
0.821745 & 0.801989 & - & 0.822156 & 0.851593 & semi & Trial and Error \\
0.840679 & 0.790841 & - & 0.822156 & 0.109681 & high & \\
\hline 0.870272 & - & - & 0.87992 & 0.299464 & low & \\
0.870449 & - & - & 0.88013 & 0.859627 & semi & Carefully \\
0.8001 & - & - & 0.129553 & 0.860264 & high & \\
\hline 0.859762 & - & 0.124506 & 0.879788 & 0.6648206 & low & \\
0.110407 & - & 0.889593 & 0.119265 & 0.8791854 & semi & Expert \\
0.131112 & - & 0.868888 & 0.120705 & 0.1207046 & high & \\
\hline
\end{tabular}

In Eqs. 8 and 9, the careful cognitive skill reference shows the weight of $q$ in $j$ class is $w_{1,, c f}=\{0.87,0.87,0.80\}$, the weight of $m$ in $j$ class is $w_{2 j, c f}=\{0.88,0.88,0.13\}$, and the weight of $c$ in $j$ class is $w_{3 j, c f}=\{0.30,0.86,0.86\}$. 
In Eqs. 10 and 11, the expert cognitive shows the weight of $q$ in $j$ class is $w_{1 j, e p}=\{0.86,0.11,0.13\}$, the weight of $e$ in $j$ class is $w_{2 j, e p}=\{0.12,0.89,0.87\}$, the weight of $m$ in $j$ class is $w_{3 j, e p}=\{0.88,0.12,0.12\}$, and the weight of $c$ in $j$ class is $w_{4 j, e p}=\{0.66,0.88,0.12\}$.

\subsection{Cognitive Skill Classification}

From Eqs. 6 until 13, it can be stated that, this research is a method implementation in game to know the three cognitive skill behaviors from 33 players (students), and three cognitive skill levels in each cognitive skill. Trial and error cognitive skill indicates low competency in playing a game. Carefully cognitive skill indicates good ability and expert cognitive skill shows players have high ability in game.

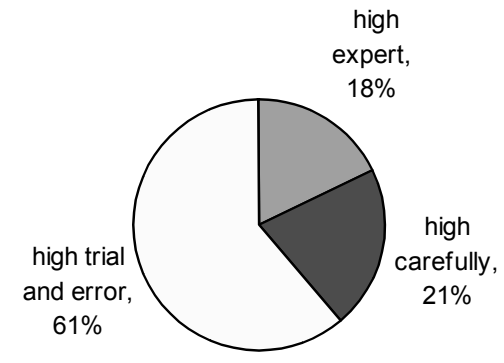

Figure 3 Classification of cognitive skill behaviors.

Sixty one percent players have high trial and error cognitive skill. Twenty one percent players have high carefully cognitive skill, while eighteen percent players have high expert cognitive skill.

\subsection{Cognitive Skill Game Multiple Objective}

The results of experiment are shown in Table 3. CSG is identified from the cognitive skills of 33 respondents.

CSG is representing the three cognitive skill references; those are trial and error, careful and expert cognitive skill references. This is the CSG multi objective. Player's performance will be strong in one cognitive skill references and weak in the other. The first objective is Expert $\left(C_{1}\right)$, the second objective is carefully $\left(C_{2}\right)$, and the third objective is trial and error $\left(C_{3}\right)$. Table 3 shows how the 33 respondents are multi-objective nature of each type of cognitive skills.

In this research, 33 respondents are playing the game to present CSG multiple objectives. 33 player's behavior shows multi-objective of trial and error, carefully and expert cognitive skill. Table 3 shows the results of experiments in 
general. To facilitate observation, we perform weighting on the value of $C_{1}, C_{2}$ and $C_{3}$.

Table 3 Results of experiments.

\begin{tabular}{|c|c|c|c|c|c|c|c|c|c|}
\hline \multirow{2}{*}{$\begin{array}{c}\text { ID } \\
\text { respondent }\end{array}$} & \multicolumn{2}{|c|}{$\begin{array}{c}\text { expert class } \\
\left(C_{1}\right)\end{array}$} & \multicolumn{2}{|c|}{$\begin{array}{l}\text { carefully } \\
\text { class }\left(C_{2}\right)\end{array}$} & \multicolumn{2}{|c|}{$\begin{array}{c}\text { trial and } \\
\text { error class } \\
\left(C_{3}\right) \\
\end{array}$} & \multirow[t]{2}{*}{$\begin{array}{c}\text { cognitive } \\
\text { skill type } \\
\text { (L) }\end{array}$} & \multirow[t]{2}{*}{$\begin{array}{l}\text { cognitive skill } \\
\text { classification } \\
(C S)\end{array}$} & \multirow[t]{2}{*}{$\begin{array}{l}\% \text { from all } \\
\text { respondents }\end{array}$} \\
\hline & valu & eight & value & weight & value & weight & & & \\
\hline 12 & high & 3 & high & 3 & low & 1 & carefully & high carefully & \\
\hline 10 & high & 3 & high & 3 & low & 1 & carefully & high carefully & \\
\hline 20 & low & 1 & high & 3 & semi & 2 & carefully & high carefully & \\
\hline 2 & high & 3 & high & 3 & low & 1 & carefully & high carefully & $21 \%$ \\
\hline 4 & semi & 2 & high & 3 & low & 1 & carefully & high carefully & \\
\hline 17 & semi & 2 & high & 3 & semi & 2 & carefully & high carefully & \\
\hline 33 & low & 1 & high & 3 & semi & 2 & carefully & high carefully & \\
\hline 9 & high & 3 & high & 3 & low & 1 & expert & high expert & \\
\hline 7 & high & 3 & low & 1 & low & 1 & expert & high expert & \\
\hline 5 & high & 3 & high & 3 & low & 1 & expert & high expert & $18 \%$ \\
\hline 11 & high & 3 & high & 3 & low & 1 & expert & high expert & \\
\hline 3 & high & 3 & high & 3 & low & 1 & expert & high expert & \\
\hline 1 & high & 3 & high & 3 & low & 1 & expert & high expert & \\
\hline 23 & high & 3 & low & 1 & high & 3 & trial and error & high trial and error & \\
\hline 15 & low & 1 & low & 1 & high & 3 & trial and error & high trial and error & \\
\hline 19 & low & 1 & low & 1 & high & 3 & trial and error & high trial and error & \\
\hline 16 & high & 3 & low & 1 & high & 3 & trial and error & high trial and error & \\
\hline 18 & low & 1 & low & 1 & high & 3 & trial and error & high trial and error & \\
\hline 8 & high & 3 & low & 1 & high & 3 & trial and error & high trial and error & \\
\hline 6 & high & 3 & low & 1 & high & 3 & trial and error & high trial and error & \\
\hline 14 & low & 1 & low & 1 & high & 3 & trial and error & high trial and error & \\
\hline 25 & low & 1 & low & 1 & high & 3 & trial and error & high trial and error & \\
\hline 13 & low & 1 & low & 1 & high & 3 & trial and error & high trial and error & $61 \%$ \\
\hline 30 & low & 1 & low & 1 & high & 3 & trial and error & high trial and error & \\
\hline 28 & low & 1 & low & 1 & high & 3 & trial and error & high trial and error & \\
\hline 22 & low & 1 & low & 1 & high & 3 & trial and error & high trial and error & \\
\hline 24 & low & 1 & low & 1 & high & 3 & trial and error & high trial and error & \\
\hline 21 & low & 1 & low & 1 & high & 3 & trial and error & high trial and error & \\
\hline 26 & low & 1 & low & 1 & high & 3 & trial and error & high trial and error & \\
\hline 27 & low & 1 & low & 1 & high & 3 & trial and error & high trial and error & \\
\hline 29 & low & 1 & low & 1 & high & 3 & trial and error & high trial and error & \\
\hline 31 & low & 1 & low & 1 & high & 3 & trial and error & high trial and error & \\
\hline 32 & low & 1 & low & 1 & high & 3 & trial and error & high trial and error & \\
\hline
\end{tabular}

\subsection{Analysis of Cognitive Skill Characteristic}

The characteristic of cognitive skill are divided into three groups, namely; high cognitive skill, middle cognitive skill, and low cognitive skill. High cognitive skill is the highest cognitive performance of the players during the process of completing a game mission. Those with high cognitive skills are experts, who are characterized as; never make mistakes, have a high competence (high self 
efficacy), always confident with high level of efficiency to answer, and finish the tasks thoroughly.

Middle cognitive skill is a cognitive performance that is good enough at the time of completing the mission of the game. Cognitive skills have good characteristics as careful, includes; few errors, low confident, low level of efficiency to answer, and finish the tasks thoroughly.

Low cognitive skill is the lowest performance of the players' cognitive during serious games. The characteristic of this skill are trial \& error, includes; tend to make many mistakes (high error factor), always try to respond or try to answer, low confident, low efficiency in answering questions and solve the problem thoroughly.

\section{Discussions}

\subsection{Multiple Objective Characteristic}

By looking at the results of Cognitive Skill Classification (section 5.2 and 5.3), Sixty one percent players have high trial and error cognitive skill. Twenty one percent players have high carefully cognitive skill, while eighteen percent players have high expert cognitive skill. We will look at the level of multiobjective character of each cognitive skills classification. Refer to the results of experiments in Table 3; value of cognitive skill multi-objective is presented in Table 4.

Table 4 Value of cognitive skill multi-objective.

\begin{tabular}{cccc}
\hline $\begin{array}{c}\text { cognitive skill } \\
\text { classification of } \\
\text { respondent }\end{array}$ & $\begin{array}{c}\text { 1st objective } \\
\text { (expert) } \\
\text { average of } \\
\boldsymbol{C}_{\mathbf{1}} \text { weights }\end{array}$ & $\begin{array}{c}\text { 2sd objective } \\
\text { (carefully) } \\
\text { average of } \\
\boldsymbol{C}_{\mathbf{2}} \text { weights }\end{array}$ & $\begin{array}{c}\text { 3rd objective (trial } \\
\text { and error) } \\
\text { average of } \\
\boldsymbol{C}_{\mathbf{3}} \text { weights }\end{array}$ \\
\hline $\begin{array}{c}\text { high expert } \\
\text { (18\% from all respondents) } \\
\text { high carefully }\end{array}$ & 3.00 & 2.67 & 1.00 \\
$\begin{array}{c}\text { (21\% from all respondents) } \\
\text { high trial and error }\end{array}$ & 2.14 & 3.00 & 1.43 \\
$(61 \%$ from all respondents) & 1.40 & 1.00 & 3.00 \\
\hline
\end{tabular}

Table 4 visualizes the multi-objective for each group of respondents with cognitive skills classification of high trial and error, high carefully and high expert. Value of weight equals to three is having a strong character objective, and on the other hand a weight with one value is having a weak character objective. 
In row expert of Table 4, the players who have expert cognitive skill character is highly multi objective with the trial and error cognitive skill character, but few with carefully cognitive skill character. This means that expert players also have the carefully character.

The multi objective character is high for the twenty one percent players who have carefully cognitive skill. In Table 4, high carefully row displays multiple objectives of carefully cognitive skills. This shows that the players with carefully cognitive skill character have high multi objective with the trial and error cognitive skill characters' and relatively high multi objective of expert cognitive skill characters' too.

In high trial and error row from Table 4 displays multiple objectives of players with classification high trial and error cognitive skill. These show that the players with trial $\&$ error cognitive skill character have highly multi objective with the carefully cognitive skill characters' and expert cognitive skill characters' too.

\section{Conclusions}

In CSG modeling research, we get the function of cognitive skill behavior identification. LVQ method is used to classify player's characteristic in playing games. The CSG is embedding sensitivity of teachers in the game. It is because CSG data training in LVQ method is taken from the teachers.

In CSG classification research, game can identify player's cognitive skill behavior. Players can be classified in three cognitive skill clusters namely; i) trial and error, ii) careful and iii) expert, by result are $18 \%$ is high expert, $21 \%$ high carefully, $61 \%$ high trial and error.

In CSG multiple objective research, we find the players with trial and error character are strong multiple objective. These players are weak in expert and carefully character. The players have carefully character, weak in trial and error character, also weak in expert character. Whereas, the players who have expert character have carefully character too but weak in trial and error character.

In education methodology (by utilizing games), mastery learning is the core of the learning process. Mastery learning can be achieved by always maintaining a high interest (included in serious game). Typical assessments are likely to disrupt the interest. CSG is embedding assessments of cognitive skills in serious game. Thus there would be less obtrusive and hence less disruptive to flow experience in a game. 
For further research, CSG can provide feed back to determine the level or used as a guide in game. Individual behavior can influence the scenario changes in game. CSG can be fun and personality challenges in serious game.

To sum up, we can conclude that the CSG is embedded assessments of cognitive skills with the sensitivity of teachers in the serious game. CSG disposed have strong multi-objective character of cognitive skills classification. Thus there is a need the optimum method based on LVQ. Indirectly, CSG always observe fluctuations in the interest of the players. CSG informed an accurate level of cognitive skills, it strongly supports the completeness learning in serious game.

\section{References}

[1] Chen, S. \& Michael, D., Proof of Learning: Assessment in Serious Games, Gamasutra, http://www.cedma-europe.org/newsletterarticles/ misc/Proof of Learning - Assessment in Serious games (Oct\%2005).pdf (23 Augustus 2010).

[2] Marsh, T., Wong, W.L., Carriazo, E., Nocera, L., Yang, K.,Varma, A., Yoon, H., Huang, Y-L, Kyriakakis, C. \& Shahabi, C., User Experiences and Lessons Learned from Developing and Implementing an Immersive Game for the Science Classroom, Information laboratory (InfoLAB), University of Southern California, http://infolab.usc.edu/DocsDemos/hci05.pdf, (17 June 2009).

[3] Clark, D., Game and E-Learning, Sunderland: Caspian Learning, www.caspianlearning.co.uk, (22 April 2009).

[4] Ndahi H., The Use of Innovative Methods to Deliver Technology Education Laboratory Courses via Distance Learning: A Strategy to Increase Enrollment, Journal of Technology Education, 2006. http://scholar.lib.vt.edu/ejournals/JTE/ v17n2/ndahi.html, (1 June 2009).

[5] Hayashi, A., Chen, C.C. \& Terase, H., Aligning IT Skills Training With Online Asynchronous Learning Multimedia Technologies, Information Systems Education Journal (ISEDJ), 3(26), http://isedj.org /3/26/ISEDJ.3(26).Hayashi.pdf (3 Juni 2009).

[6] Ololube, N.P., Appraising The Relationship Between ICT Usage and Integration and The Standard of Teacher Education Programs in A Developing Economy, International Journal of Education and Development using Information and Communication Technology (IJEDICT), 2(3), pp. 70-85, 2006.

[7] Arnseth, H.C., Learning to Play or Playing to Learn - A Critical Account of the Models of Communication Informing Educational Research on Computer Gameplay, The International Journal of Computer Game 
Research, 6(1), http://gamestudies.org/0601/articles/arnseth, (26 April 2009).

[8] Smith, J.H., The Games Economists Play - Implications of Economic Game Theory for the Study of Computer Games, The International Journal of Computer Game Research, 6(1), http://gamestudies.org/ 0601/articles/heide_smith, (16 April 2009)

[9] Clark, R.E., Evaluating the Learning and Motivation Effects of Serious Games, Rosier school of Education Center for Creative Technologies, http://projects.ict.usc.edu/itgs/talks/Clark_Serious Games Evaluation.ppt, (28 Augustus 2010).

[10] Mayer, R.E., Should There Be A Three-Strikes Rule Against Pure Discovery Learning, American Psychologist, 59(1), pp. 14-19, 2004.

[11] Kirschner, P., Sweller, J., \& Clark, R.E., Why Minimally Guided Learning Does Not Work: an Analysis of The Failure of Discovery Learning, Problem-Based Learning, Experiential Learning and InquiryBased Learning, Educational Psychologist, 41(2), pp. 75-86, 2006.

[12] Clark, R.E. \& Choi, S., Five Design Principles for Experiments on The Effects of Animated Pedagogical Agents, Journal of Educational Computing Research, 32(3), pp. 209-223, 2005.

[13] Inal, Y. \& Cagiltay, K., Flow Experiences of Children in An Interactive Social Game Environment, British Journal of Educational Technology, 38 (3), pp. 455-464, 2007.

[14] Shute, V.J., Ventura, M., Bauer, M., \& Rivera, D.Z., Melding the Power of Serious Games and Embedded Assessment to Monitor and Foster Learning: Flow and Grow, Parson, http://a.parsons.edu/ loretta/ Fassessment_archive/GAMES_Shute_FINAL.pdf (5 October 2011)

[15] Bosch, P., Dalinghaus, K., Hammer, B., Reuter, J-P., Schrader, B., Steffens, T. \& Umbach, C., Cognitive Architecture: The Integration of Rules and Patterns, Institute of Cognitive Science University of Osnabrück, 2003.

[16] Conde, T. \& Thalmann, D., Autonomous Virtual Agents Learning a Cognitive Model and Evolving, EPFL Virtual Reality Lab, IVA 2005, LNCS 3661, pp. 88-98, 2005.

[17] Conati C. \& Klawe M., Socially Intelligent Agents in Educational Games, University of British Columbia, citeseerx.ist.psu.edu/viewdoc/ download?doi=10.1.1.6.6209\&rep=rep1\&type=pdf (7 June 2011).

[18] Isnaini, H., Classification Efficiency Problem Solving Integer Arithmetic Operation Junior High School Class 7 With Game Using LVQ Method, Master Theses of Electrical Engineering, Department of Electrical Engineering FTI, Institut Teknologi Sepuluh Nopember (ITS), Surabaya, 2009. 
[19] Harini, S.M., Classification of Comprehensive Learning Achievement Effectivity in Senior High School Students Based on Mathematical Logic Game Using LVQ Method, Master Theses of Electrical Engineering, Department of Electrical Engineering FTI, Institut Teknologi Sepuluh Nopember (ITS), Surabaya, 2009.

[20] Syufagi, M.A., Hariadi, M. \& Purnomo, M.H., Model of Mental Effort Assessment in Pedagogic Games Based On LVQ Method, SESINDO2008 Conference, Department of Information System FTI ITS ISBN: 978-979-18985-0-8, pp. 556-564, 2008

[21] Abramson, M. \& Wechsler, H., A Distributed Reinforcement Learning Approach to Pattern Inference in Go, CiteSeerx, http://citeseerx.ist.psu. edu/viewdoc/download?doi=10.1.1.9.7035, (7 June 2011).

[22] Kohonen, T., Hynninen, J., Kangas, J., Laaksonen, J. \& Torkkola K., LVQ_PAK The Learning Vector Quantization Program Package Version 3.1 (April 7, 1995), The LVQ Programming Team of the Helsinki University of Technology Laboratory of Computer and Information Science, Rakentajanaukio 2 C, SF-02150 Espoo FINLAND, 1995.

[23] Chen, C-R., Tsai, L-T. \&Yang, C-C., A Neural Network Approach for Random Samples to Stratified Psychometrical Population, Proceedings of the WSEAS International Conference on SOCIOLOGY, PSYCHOLOGY, PHILOSOPHY, pp. 51-54, Penang, 2010.

[24] Song, H-H. \& Lee, S-W., LVQ Combined with Simulated Annealing for Optimal Design of Large-set Reference Models, Neural Networks, 9(2), pp. 329-336, Elsevier Science Ltd, 1996

[25] Kim, D.K., Lee, S.H., Kim, B-S. \& Moon G., Generalized LVQ for Optimal Reference Vectors using a Differentiable MIN Module, Proceedings of International Conference on Neural Information Processing, pp. 1937-1942, Seoul, 1994. 